Article

\title{
Fatigue and Durability of Laminated Carbon Fibre Reinforced Polymer Straps for Bridge Suspenders
}

\author{
Fabio Baschnagel ${ }^{1}$, Rea Härdi ${ }^{1,2}{ }^{\text {, Zafiris Triantafyllidis }}{ }^{3}$, Urs Meier ${ }^{4}$ and \\ Giovanni Pietro Terrasi 1,3,* \\ 1 Mechanical Systems Engineering Laboratory, Empa, Swiss Federal Laboratories for Materials Science and \\ Technology, Ueberlandstrasse 129, 8600 Duebendorf, Switzerland; fabio.baschnagel@empa.ch (F.B.); \\ haerdire@student.ethz.ch (R.H.) \\ 2 Department of Materials, ETH Zuerich, 8093 Zuerich, Switzerland \\ 3 Institute for Infrastructure and Environment, School of Engineering, the University of Edinburgh, \\ Edinburgh EH9 3FG, UK; z.triantafyllidis@ed.ac.uk \\ 4 Empa, Swiss Federal Laboratories for Materials Science and Technology, Ueberlandstrasse 129, \\ 8600 Duebendorf, Switzerland; urs.meier@empa.ch \\ * Correspondence: giovanni.terrasi@empa.ch; Tel.: +41-587-654-117
}

Received: 15 December 2017; Accepted: 7 February 2018; Published: 10 February 2018

\begin{abstract}
Steel cables and suspenders in bridges are at high risk of corrosion-fatigue and in some cases of fretting-fatigue in their anchorages. These factors greatly limit the service stresses of a specific cable system and involve expensive protection measures. In order to investigate the above limitations, the fretting fatigue behaviour of pin-loaded carbon fibre reinforced polymer (CFRP) straps was studied as models for corrosion-resistant bridge suspenders. Two types of straps were tested: small model straps with a sacrificial CFRP ply and large full-scale straps. In a first phase, five fully laminated and carbon pin-loaded CFRP model straps were subjected to an ultimate tensile strength test. Thereafter, and in order to assess their durability, 20 model straps were subjected to a fretting fatigue test, which was successfully passed by 4 straps. An S-N curve was generated for a load ratio of 0.1 and a frequency of $10 \mathrm{~Hz}$. In a second phase, one full-scale strap was tested for its ultimate tensile strength and two full-scale straps were fatigue-tested. The influence of fretting fatigue loading on the residual mechanical properties of the straps was also assessed, and although fretting fatigue represented an important limitation for laminated CFRP straps, it could be shown that the investigated CFRP tension members can compete with the well-established steel suspenders.
\end{abstract}

Keywords: carbon fibre reinforced polymer; CFRP; fatigue; tensile elements; bridge suspenders

\section{Introduction}

Carbon fibre reinforced polymers (CFRP) have attracted significant attention in the past few decades as alternative materials to steel for tendons and suspension cables due to their superior strength and stiffness, low weight, and excellent resistance to corrosion, fatigue, and creep. Despite these favourable characteristics of CFRP materials, their widespread implementation was partially hindered by significant challenges regarding their anchorage to structural elements (mainly due to the anisotropic nature of CFRP as opposed to steel). Although simple approaches, such as clamping devices for quasi-static tensile loads, have been developed in the recent past [1,2], the anchorage of fatigue loads poses a serious limitation to such clamping anchorage systems. Thus, complex anchoring systems are required to ensure full exploitation of the tendon properties under fatigue loads $[1,3]$. To overcome this complexity, pin-loaded looped CFRP straps have been suggested by Meier and Winistoerfer [4] as practical tensile elements that are stressed by load transfer through the pins without the need for additional anchoring systems. Nowadays, pin-loaded unidirectional (UD) CFRP straps are 
widely implemented as rigging systems in the sailing industry and particularly in racing sailboats $[5,6]$. They have also emerged in the crane industry as an alternative to steel pendant links in crawler cranes, allowing for improved lifting capacities and easier self-erecting assembly [7]. Furthermore, pin-loaded CFRP straps have been used successfully as tendons in the bowstring arch pedestrian bridge at the Swiss Federal Laboratories for Materials Testing and Research, Empa, Switzerland [8], and they have been recently proposed as deck suspenders in arch bridges [9]. In half-through and through arch bridges, the corrosion and fatigue of conventional steel suspenders is a critical factor that limits their design lifespan. Hence, there is a high potential in using corrosion- and fatigue-resistant pin-loaded CFRP straps for this purpose [9]. The current paper is aimed at studying the fatigue behaviour of these novel tensile elements in order to provide useful insights for the development of durable pin-loaded CFRP strap suspension systems.

In CFRP composites, the damage modes and crack propagation characteristics are considerably more complex compared to isotropic materials, such as metals, ceramics, or unreinforced polymers. They depend on a multitude of factors, such as the fibre and matrix types, the fibre sizing (thus, the fibre-matrix interaction), the layup sequence of the laminate, and the loading conditions, amongst many others [10-13]. A general characterisation of the fatigue behaviour of multiaxial fibre reinforced polymer composites (FRPs) was given by Reifsnider and Highsmith [14], who divided it into three different stages. In the first stage, damage develops at a very rapid rate within the first $10-15 \%$ of the life of the laminate, with the primary damage mode being cracking of the matrix in the laminae with the most off-axis fibre orientation. This intralaminar matrix cracking between the fibres reaches uniform saturation spacing at the end of stage I, which is called the characteristic damage state (CDS). In stage II, corresponding to $70-80 \%$ of the fatigue life, damage is still initiated and the existing damages continue to grow, although at a considerably slower rate, until the laminate is severely damaged. Finally, in stage III, the damage process is accelerated again until ultimate failure of the laminate.

In the case of purely unidirectional CFRP laminates where no off-axis plies are present, the only limiting factors in the fatigue life are the matrix and its interaction with the fibres [15-17] since carbon fibres show excellent fatigue behaviour [18]. Based on a review of the fatigue damage mechanisms, Talreja [19] introduced a fatigue life diagram in which he suggests that the fatigue life of a unidirectionally reinforced polymer is governed by the quasi-static fracture strain of the composite and the matrix fatigue limit strain. Given the insensitiveness of the fibres to fatigue and neglecting possible fretting, the diagram states that no damage progression takes place in the composite below the matrix fatigue limit strain $\left(\varepsilon_{m f}\right)$ [19], for which Talreja considered a value of $\varepsilon_{m f}=0.6 \%$ based on experimental data for epoxy resins given by Dharan [20]. Hence, a matrix strain of $0.6 \%$ can be used as a minimum limit strain for epoxy fatigue when designing for the fatigue endurance limit.

When CFRP elements are in frictional contact with other components and subjected to relative cyclic displacement, their fatigue life can be drastically reduced due to the fretting process that occurs at the material interfaces. In general, the fretting wear performance of FRP laminates depends on many different factors, such as the fibre and matrix materials, the fibre orientation, the sliding direction, the contact pressure on the fretted surface, the amplitude and frequency of the reciprocating motion, the hardness of the contacting material, surface treatments, lubrication, and interfacial temperature conditions [21-25]. As regards the sliding direction specifically, the highest wear resistance occurs when sliding occurs parallel to the fibres, and the lowest for sliding perpendicular to the fibres [26-28]. In their pioneering study on the fretting fatigue behaviour of CFRP laminates, Schulte et al. [21,29,30] observed reductions up to three orders of magnitude in the fatigue life of laminates that were exposed to fretting on their $0^{\circ}$ (load carrying) fibre plies, compared to those tested under plain fatigue. However, only slight deviations were observed in the fretting and plain fatigue behaviour of laminates if their outer plies comprised off-axis $\left( \pm 45^{\circ}\right)$ fibres [21]. In the case of sliding parallel to the load-bearing longitudinal fibres, the effects of fretting wear are detrimental to the fatigue life of the laminate. On the other hand, for laminates comprising distinct off-axis fibres at the fretted surface, the fatigue life is comparatively less sensitive to the fretting component despite the higher wear rate of the outer ply as 
compared to sliding along longitudinal fibres. This is because by (sacrificially) damaging the outer off-axis plies, the underlying load-bearing longitudinal plies are protected [21].

These phenomena are highly relevant to the durability of CFRP straps in applications such as those described above, since they are subjected to fatigue loading while being in frictional contact with the pins. In a previous study by the authors [31], the fretting fatigue behaviour of laminated unidirectional CFRP straps as suspender models was investigated. The current paper studies the fretting fatigue behaviour of model straps (MS) comprising an additional sacrificial fibre ply between the innermost ply of the looped CFRP strap and the loading pin. Introducing a thin, low-stiffness/toughness fibre ply (e.g., glass: GFRP) between the innermost ply of the CFRP strap and the loading pin has been suggested by Schürmann [32] as a way to reduce the stress concentrations at the curved part of the strap. In addition to this function, such a ply is considered in the current paper as sacrificial protection against fretting of the load-bearing $0^{\circ}$ fibres of the CFRP strap. Because a glass fibre reinforcement significantly reduces the fretting wear resistance of the composite laminates [22], a carbon fibre sacrificial ply was used instead. This comprised a woven fabric with fibres oriented in the $\pm 45^{\circ}$ direction, such that their influence on the axial stiffness of the strap is reduced, while still retaining significant resistance to fretting, as opposed to transversely oriented fibres [21]. Another expected advantage of using a fabric made of carbon was that a possible fretting product might be graphite, which is known to be a good lubricant under the right conditions [33].

Finally, in addition to the small-scale model straps, the behaviour of pristine full-scale laminated CFRP straps (FSS) in fretting fatigue tests without a sacrificial ply is also discussed.

\section{Materials and Methods}

\subsection{Materials}

The investigated CFRP straps were manufactured from out of autoclave (OOA) prepreg. The unidirectional tapes were manufactured by Carbo-Link AG in Fehraltorf, Switzerland, with widths of $12 \pm 1$ and $48 \pm 1 \mathrm{~mm}$ for the model and full-scale straps, respectively, using intermediate modulus Tenax ${ }^{\circledR}$-J IMS60 carbon fibre rovings by Toho Tenax Europe GmbH, Wuppertal, Germany, [34] in combination with the hot melt epoxy matrix system XB3515/Aradur ${ }^{\circledR} 5021$ by Huntsman Advanced Materials $\mathrm{GmbH}$, Basel, Switzerland, [35]. The two tapes contained 3 and 12 rovings, respectively, with 24,000 fibres per roving. The carbon fibres had a reported tensile strength of $5800 \mathrm{MPa}$ and a Young's modulus of $290 \mathrm{GPa}$ [34], and the tape was reported to have a fibre volume content $\left(V_{f}\right)$ of $62 \pm 2 \%$ and a weight of $290 \mathrm{~g} / \mathrm{m}^{2}$ [36]. $V_{f}$ measurements by sulphuric acid digestion of the epoxy according to [37] revealed an average $V_{f}$ of $64.8 \%$. The OOA prepreg used for the sacrificial ply of the model straps and for the confinement of the transition zone in the full-scale straps used the same matrix system as the unidirectional tape but consisted of HexTow ${ }^{\circledR}$ AS4 carbon fibres by Hexcel Corporation, Stamford, CT, USA, with a reported Young's modulus of $231 \mathrm{GPa}$ and a tensile strength of $4619 \mathrm{MPa}$ [38]. The fibres were weft in $2 \times 2$ twill style to a fabric with a grammage of $193 \mathrm{~g} / \mathrm{m}^{2}$. The final prepreg grammage was reported to be $343 \mathrm{~g} / \mathrm{m}^{2}$ [36].

The pins used for loading the small-scale model straps were pultruded T300 CFRP pins with a diameter of $20 \mathrm{~mm}$ and a reported $V_{f}$ of 60-65\% [39]. For the loading of the full-scale straps, $60 \mathrm{~mm}$ wide titanium connector eyes with an inner and outer diameter of $d_{i}=90 \mathrm{~mm}$ and $d_{0}=200 \mathrm{~mm}$ were used. A $10 \mathrm{~mm}$ deep and $50 \mathrm{~mm}$ wide circumferential notch in the connector eyes ensured a proper positioning and lateral support of the laminate.

\subsection{Manufacturing}

Both types of straps were manufactured using a winding process. The model straps were laminated in a similar process to that previously described in [31]. In order to accommodate the sacrificial plies in the curved (contact) areas without influencing the orientation of the unidirectional (load-carrying) fibres, the aluminium mould described in [31] had to be adjusted. Figure 1 illustrates 
how the thinner segments (grooves) of the mould, around which the tapes were wound, were thickened in the shaft region by $0.25 \mathrm{~mm}$ on each side (i.e., the thickness of the woven CFRP ply) such that the load-carrying unidirectional fibres were not bent during the lamination process. As an improvement to the lamination process described in [31], the laminate was compressed by two clamps that were screwed together in the shaft region of the straps. This was to ensure a well-defined laminate quality in critical (curved) regions of the model straps. The model straps had a nominal shaft length $L$ of $250 \mathrm{~mm}$, a nominal width and thickness of $12 \mathrm{~mm}$ and $1 \mathrm{~mm}$, respectively, and an inner radius of curvature of $10 \mathrm{~mm}$, see Figure 2a. The thickness of the laminate was chosen such that the ratio of outer to inner radius of curvature (a ratio of 1.1) was similar to that of the full-scale straps. This has been reported in the literature to be the governing factor for the tensile efficiency of laminated unidirectional FRP composite straps [40].

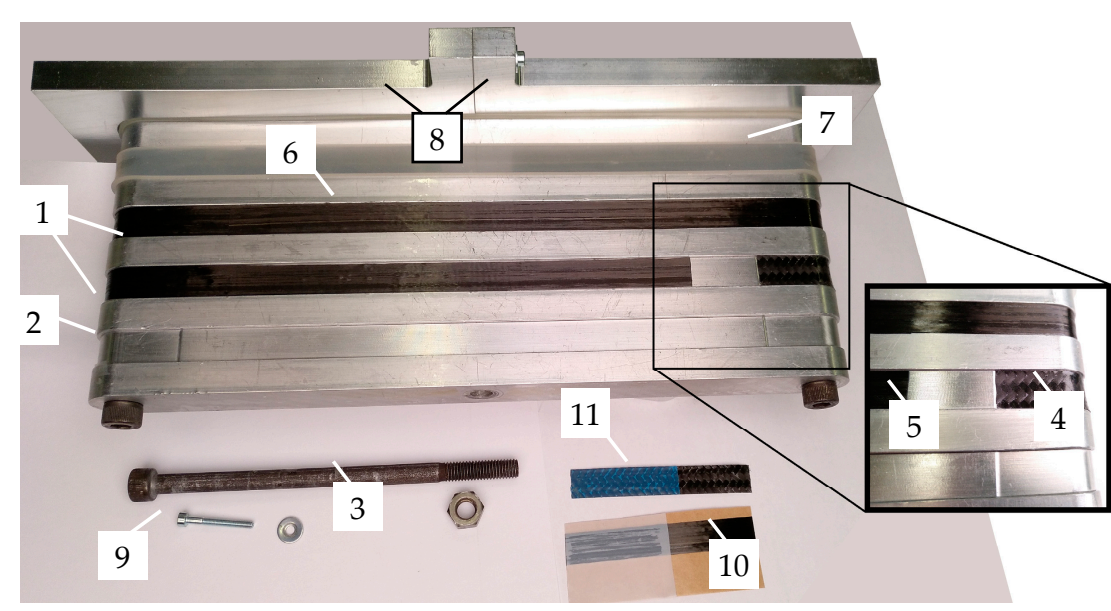

1) $24.8 \mathrm{~mm}$ thick segments

2) $20.5 \mathrm{~mm}$ thick segments

3) $\mathrm{M} 8 \times 140 \mathrm{~mm}$ screw

4) sacrificial twill ply

5) start of innermost ply

6) laminated model strap

7) silicone tape

8) clamps

9) $\mathrm{M} 3 \times 40 \mathrm{~mm}$ screw

10) UD tape

11) $70 \mathrm{~mm}$ long twill tape

Figure 1. Mould for lamination of the model carbon fibre reinforced polymer (CFRP) straps with a sacrificial ply in the contact areas.

The full-scale straps were manufactured by winding the $48 \mathrm{~mm}$ wide tape directly around the two titanium connector eyes to a final thickness of $10 \mathrm{~mm}$ using a tape laying machine [41]. The transition zone between connector eyes and shaft was internally supported with proprietary foam [42] and externally confined with the woven twill fabric described above in order to restrain the mode I opening forces acting on the shaft under tensile loads. Then, shrinking tape was wound around the free length and transition zone of the straps in the circumferential direction. This ensured proper compaction of the laminate during the curing process and a circular cross-sectional area over the free length in the final full-scale straps. The three full-scale straps were denominated FSS A, B, and C, had a cross-sectional area of 871,860 , and $845 \mathrm{~mm}^{2}$ and a length of 3012,3015 , and $3017 \mathrm{~mm}$, respectively. Figure $2 \mathrm{c}$ shows a full-scale strap before testing.

Both types of straps were cured at $140{ }^{\circ} \mathrm{C}$ for $2.5 \mathrm{~h}$.

\subsection{Experimental Setup}

Figure $2 \mathrm{~b}$ illustrates the test setup of a model strap and pin in the testing machine. The ultimate tensile strength and fretting fatigue tests on the model straps were conducted on a servo-hydraulic testing machine (type 1251, Instron ${ }^{\circledR}$, High Wycombe, UK). The tensile strength tests were performed under displacement-control at a cross-head speed of $2 \mathrm{~mm} / \mathrm{min}$. The corresponding fatigue tests were performed under (peak-) load-control at a frequency $f$ of $10 \mathrm{~Hz}$ and a load ratio $R$ of 0.1 . The pultruded CFRP pins were placed in fork-like steel adapters that are screwed to the crosshead and pulsator of the testing machine. Figure $2 \mathrm{~b}$ also shows the type $\mathrm{K}$ thermocouple that was attached to the outside of the straps during the fatigue tests in order to monitor the temperature development in the critical (vertex) area. It was considered important to assess the temperature increases, e.g., from hysteretic 
heating at high test frequencies or due to fretting, because they can reduce the fatigue performance of a composite structure.

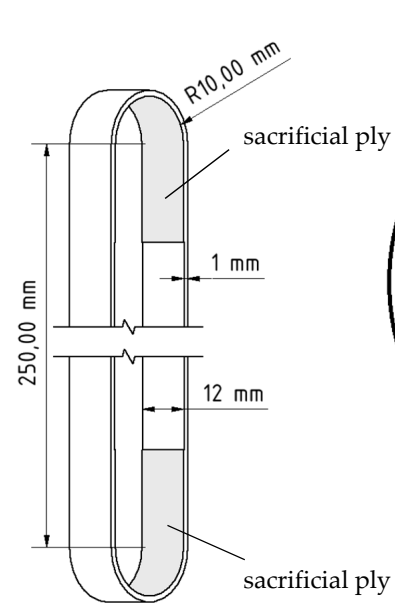

(a)

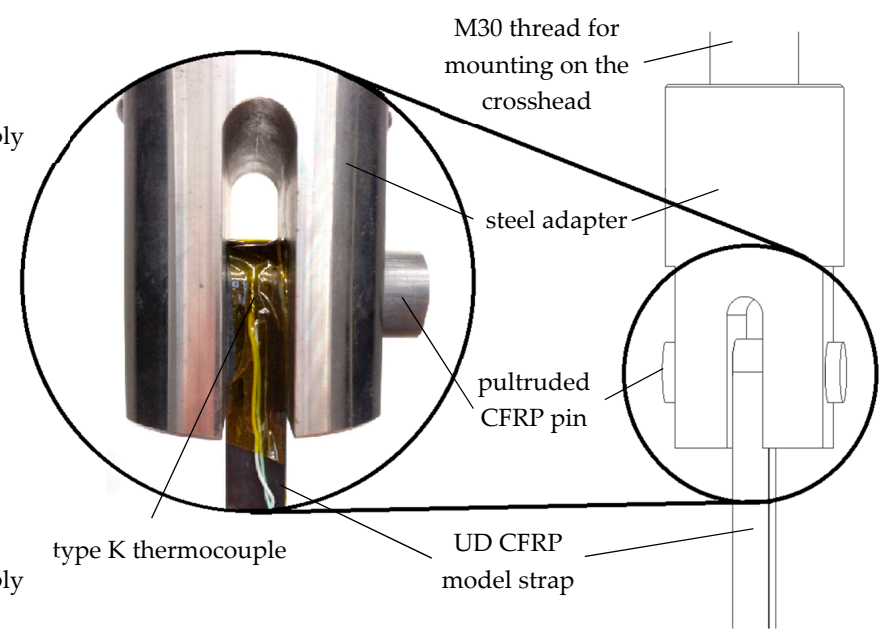

(b)

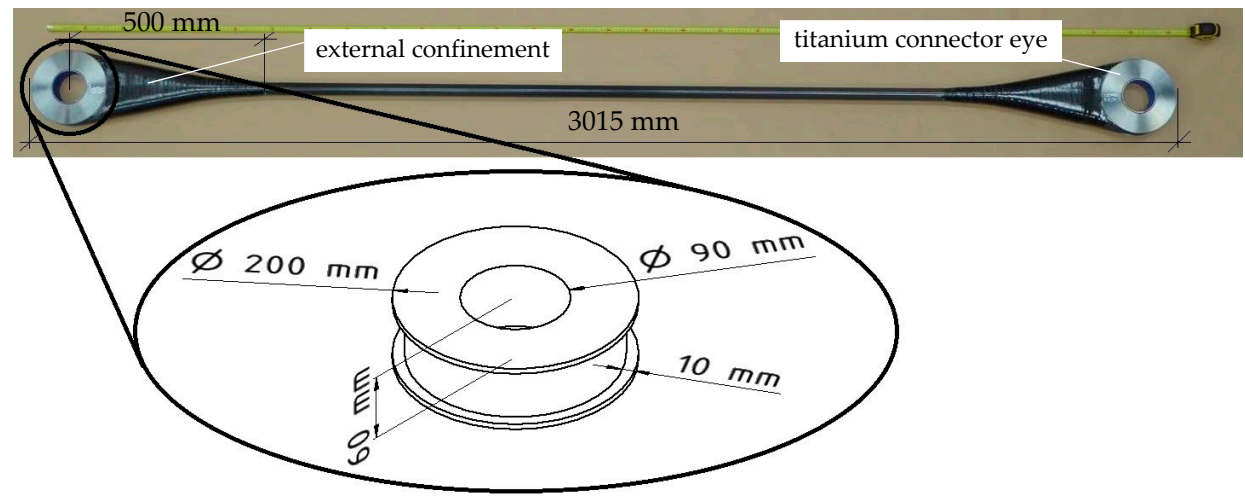

(c)

Figure 2. Investigated unidirectional CFRP straps: (a) dimensions of the model straps; (b) test setup of the model straps on the testing machine; (c) pristine full-scale strap before testing with detail of the titanium connector eye.

The full-scale straps were tested on an in-house testing machine containing an Amsler P960 pulsator. The titanium connectors of the full-scale straps were mounted on a metal bolt with an intermediate plain-bearing brush. The quasi-static tensile strength test of FSS C was performed under force-control at $90 \mathrm{kN} / \mathrm{min}$. FSS A was fatigue-tested at a frequency of $4.2 \mathrm{~Hz}$ and $R=0.2$ for 800,000 load cycles $(N)$ and an additional $11.6 \times 10^{6}$ load cycles at a load ratio of 0.42 . The corresponding upper load levels $\left(F_{u}\right)$ were 575 and $462 \mathrm{kN}$, respectively. FSS B was fatigue-tested at a load ratio of 0.42 and a frequency of $4.2 \mathrm{~Hz}$ for $11.3 \times 10^{6}$ load cycles at $F_{u}=462 \mathrm{kN}$.

\section{Results}

Thickness measurements of the model straps revealed a high scatter originating from their manufacturing process. A measured width variation of $\pm 1 \mathrm{~mm}$ in the prepreg tape led to local discontinuities in the overlapping of the individual plies during lamination, resulting in extra plies if the tape was too wide or lacking plies wherever the tape was less than $12 \mathrm{~mm}$ wide. The chosen clamping system was not able to cope with these discontinuities and compact the laminate evenly, which resulted in a standard deviation of $10 \%$ of the laminate thickness. Hence, there were comparatively large local thickness variations in the model straps that made it difficult to determine the exact cross-sectional 
area of the straps and thus also the acting stresses in the model straps. As all model straps were manufactured from the same $12 \mathrm{~mm}$ wide tape and all full-scale straps were manufactured from the same $48 \mathrm{~mm}$ wide tape, for a better comparison of the two strap types, the apparent fibre stress in the straps $\left(\sigma_{a f s}\right)$ is introduced and used throughout this study. It is calculated as follows:

$$
\sigma_{a f s}=\frac{F}{A_{f}}
$$

with $F$ being the load (in $(\mathrm{N})$ ) and $A_{f}$ the total cross-sectional area $\left(\right.$ in $\left(\mathrm{mm}^{2}\right)$ ) of the unidirectional fibres in the shaft area in the respective strap. Due to the same amount of plies in each of the respective straps, this cross-sectional area was constant at a value of $16.96 \mathrm{~mm}^{2}$ for the model straps and $531.56 \mathrm{~mm}^{2}$ for the full-scale straps. The fibres of the sacrificial twill ply are excluded, since they are only applied locally and do not contribute to the load-bearing capacity of the strap in the shaft areas. With a Young's modulus ratio of approximately 1:100 between the epoxy matrix and the IMS60 fibres and a $V_{f}$ of $64.8 \%$, the contribution of the matrix to the load-bearing capacity in the strap shafts is less than $0.5 \%$ and is therefore neglected as well.

\subsection{Quasi-Static Behaviour}

In order to quantify the performance of the investigated straps under cyclic fretting fatigue loads, their pristine load-carrying capacity under quasi-static tensile loads had to be assessed first. Hence, five model straps and one full-scale strap were subjected to quasi-static tensile tests until failure. Table 1 lists the strength and stiffness values obtained from these tests.

Table 1. Quasi-static tensile strength and stiffness values of one full-scale strap and five model straps. The apparent fibre parallel elastic modulus $E_{11, \text { af }}(\mathrm{GPa})$ was calculated from linear encoder measurements following [43] using the respective fibre cross-sectional areas $\left(A_{f}\right)$. The apparent ultimate tensile stresses $\left(\sigma_{a f s, \max }\right)$ and loads $\left(F_{\max }\right)$ are also given.

\begin{tabular}{cccc}
\hline Strap & $\boldsymbol{F}_{\max }(\mathbf{k N})$ & $\sigma_{a f s, \max }(\mathbf{M P a})$ & $\boldsymbol{E}_{\mathbf{1 1 , a f}}(\mathrm{GPa})$ \\
\hline MS23 & 47.171 & 2781 & 262.614 \\
MS25 & 41.441 & 2443 & 297.391 \\
MS37 & 39.009 & 2299 & 248.343 \\
MS40 & 42.888 & 2528 & 278.469 \\
MS41 & 40.447 & 2384 & 301.277 \\
$\varnothing$ & $42.2 \pm 3.1$ & $2485 \pm 185$ & $277.619 \pm 22.5$ \\
FSS C & 1809 & 3403 & - \\
\hline
\end{tabular}

The similar straps of the previous study [31] that did not have a sacrificial ply were characterised by an average tensile strength of 1,624 $\pm 121 \mathrm{MPa}$. This corresponds to an apparent fibre stress of $2368 \pm 205 \mathrm{MPa}$ at an average maximum tensile load of $40.2 \pm 3.4 \mathrm{kN}$. The reported Young's Modulus of the straps in [31] of $175.8 \pm 12.1 \mathrm{GPa}$ corresponds to an apparent Young's Modulus of $259.9 \pm 15.2$ GPa. Comparing the results in Table 1 with [31], it can be said that the model straps with an additional, sacrificial ply in the curved areas show marginally higher strength $(+4.9 \%)$ and stiffness $(+6.8 \%)$ values at marginally higher coefficients of variation (CoV: ratio of standard deviation to the mean value) compared to model straps without a sacrificial ply. The full-scale strap reached a significantly higher apparent ultimate tensile stress $\left(\sigma_{a f s, \max }\right)$ than that of the model straps $(+36.9 \%)$.

\subsection{Fretting Fatigue}

Figure 3 shows the S-N curve obtained from the quasi-static and fretting fatigue testing of 25 pin-loaded model straps with a sacrificial ply (circular markers). As the pristine model straps with a sacrificial ply performed equal to the pristine straps tested in [31] under quasi-static loading, it was expected that they would perform even better under cyclic fretting fatigue loading. Therefore, the first fatigue tests were performed at an upper load level $\left(F_{u}\right)$ of $60 \%$ of the quasi-static tensile strength 
of the model straps. At this load level, the straps already failed prematurely at less than $10^{4}$ load cycles. In order to determine the fatigue limit load of the model straps with a sacrificial ply, $F_{u}$ was continuously reduced. At load levels below $55 \%$ of the pristine tensile strength of the model straps, the first straps endured more than 1 Million load cycles. However, out of those six straps, only four did so without failure. Two of the straps tested for $N>10^{6}$, at $52.5 \%$ and $53.5 \%$ of the pristine $F_{\max }$, failed after 2.1 and 9.7 million load cycles, respectively.

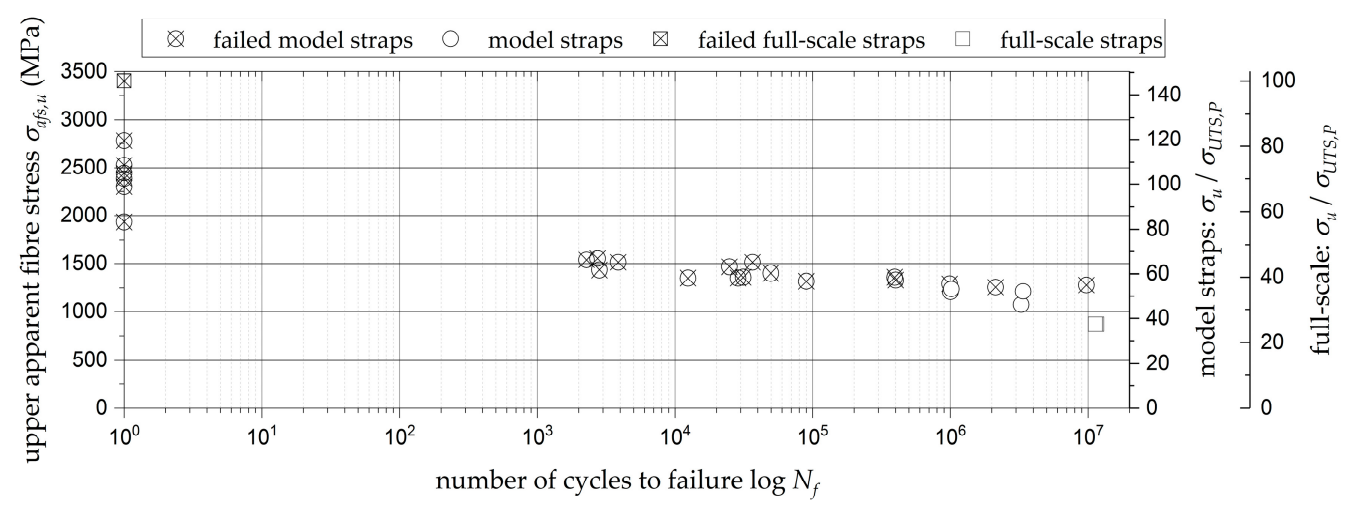

Figure 3. S-N curve of the model straps with a woven CFRP sacrificial ply (circular markers) and the full-scale straps (square markers). Listed are the upper apparent fibre stresses $\left(\sigma_{a f s, u}\right)$ over the number of endured load cycles $\left(N_{f}\right)$. Data points containing a cross indicate failed straps.

Although the full-scale straps were tested at a different frequency and load ratio $(f=4.2 \mathrm{~Hz}$, $R=0.2,0.42$ ) than the model straps, the results from the full-scale strap tests (square markers) are also included in Figure 3. Both full-scale straps tested at $25.5 \%$ of the pristine full-scale strap tensile strength endured more than $11 \times 10^{6}$ load cycles without failure (see also Table 2).

Table 2. Summary of all fretting fatigue tests conducted in this study. Given are the absolute upper load $F_{u}(\mathrm{kN})$, the apparent upper fibre stress $\sigma_{a f s, u}(\mathrm{MPa})$, the number of tested cycles $N$, the corresponding load ratio $R$, the testing frequency $f(\mathrm{~Hz})$, and the information on whether the respective strap suffered from premature failure or not.

\begin{tabular}{ccccccc}
\hline Strap & $\boldsymbol{F}_{\boldsymbol{u}}(\mathbf{k N})$ & $\left.\sigma_{a f s, \boldsymbol{u}} \mathbf{( M P a}\right)$ & Tested cycles $\boldsymbol{N}(-)$ & Load ratio $\boldsymbol{R}(-)$ & Frequency $\boldsymbol{f} \mathbf{( H z )}$ & Failure \\
\hline MS34 & 26.106 & 1539 & 2276 & 0.1 & 10 & yes \\
MS33 & 26.373 & 1555 & 2737 & 0.1 & 10 & yes \\
MS35 & 24.360 & 1436 & 2823 & 0.1 & 10 & yes \\
MS39 & 25.684 & 1514 & 3864 & 0.1 & 10 & yes \\
MS44 & 22.927 & 1351 & 12,423 & 0.1 & 10 & yes \\
MS27 & 24.900 & 1468 & 24,900 & 0.1 & 10 & yes \\
MS28 & 22.931 & 1352 & 28,755 & 0.1 & 10 & yes \\
MS24 & 23.065 & 1360 & 31,300 & 0.1 & 10 & yes \\
MS38 & 25.684 & 1514 & 36,606 & 0.1 & 10 & yes \\
MS29 & 23.780 & 1402 & 49,729 & 0.1 & 10 & yes \\
MS47 & 22.376 & 1319 & 90,007 & 0.1 & 10 & yes \\
MS42 & 23.084 & 1361 & 394,770 & 0.1 & 10 & yes \\
MS49 & 22.563 & 1330 & 401,058 & 0.1 & 10 & yes \\
MS50 & 21.955 & 1294 & 989,067 & 0.1 & 10 & yes \\
MS32 & 20.485 & 1208 & $1,002,100$ & 0.1 & 10 & yes \\
MS30 & 21.018 & 1239 & $1,015,490$ & 0.1 & 10 & no \\
MS48 & 21.336 & 1258 & $2,129,280$ & 0.1 & 10 & yes \\
MS31 & 18.202 & 1073 & $3,267,560$ & 0.1 & 10 & no \\
MS46 & 20.596 & 1214 & $3,373,240$ & 0.1 & 10 & no \\
MS45 & 21.720 & 1280 & $9,723,500$ & 0.1 & 10 & yes \\
FSS A & 575 & 1082 & 800,000 & 0.2 & 4.2 & no \\
FSS B & 462 & 869 & $11,600,000$ & 0.42 & 4.2 & no \\
\hline
\end{tabular}




\subsection{Residual Mechanical Properties}

The residual mechanical properties of the straps that did not fail under cyclic fretting fatigue loading were assessed in quasi-static tensile tests as described in Section 2.3. Table 3 lists the results of these tests.

Table 3. Residual mechanical properties of the straps tested without failure. Given are the upper load level during the cyclic fretting fatigue tests $\left(\sigma_{a f s, u}\right)$ in $(\mathrm{MPa})$, the number of cycles tested $(N)$, the maximum residual tensile load carrying capacity $\left(F_{r, \max }\right)$ in $(\mathrm{kN})$ and $(\%)$ of $F_{\max }$, the apparent maximum residual tensile stress $\left(\sigma_{r, a f s, \max }\right)$ in $(\mathrm{MPa})$ and the apparent residual fibre parallel Young's Modulus $\left(E_{r 11, a f}\right)$ in $(\mathrm{GPa})$ and $(\%)$ of $E_{11, a f}$.

\begin{tabular}{|c|c|c|c|c|c|c|c|}
\hline \multirow{2}{*}{ Strap } & \multirow{2}{*}{$\frac{\sigma_{a f s, u}}{(\mathbf{M P a})}$} & \multirow{2}{*}{$N$} & \multicolumn{2}{|c|}{$F_{r, \text { max }}$} & \multirow{2}{*}{$\begin{array}{c}\sigma_{r, a f s, \max } \\
(\mathrm{MPa})\end{array}$} & \multicolumn{2}{|c|}{$E_{r 11, a f}$} \\
\hline & & & $(\mathbf{k N})$ & $(\%)$ & & (GPa) & $(\%)$ \\
\hline MS30 & 1239 & $1,015,494$ & 40.878 & 96.95 & 2410 & 252.407 & 90.92 \\
\hline MS31 & 1073 & $3,267,564$ & 42.766 & 101.43 & 2521 & 240.496 & 86.63 \\
\hline MS32 & 1208 & $1,002,102$ & 43.049 & 102.10 & 2538 & - & - \\
\hline MS46 & 1214 & $3,373,241$ & 42.526 & 100.86 & 2507 & 253.425 & 91.29 \\
\hline$\varnothing$ & $1183 \pm 75$ & - & $42.3 \pm 0.98$ & $100.3 \pm 2.3$ & $2494 \pm 57$ & $248.8 \pm 7$ & $89.6 \pm 2.6$ \\
\hline FSS A & 869 & $11,600,000$ & 1302.48 & 72.00 & 2450 & - & - \\
\hline FSS B & 869 & $11,300,000$ & 1411.02 & 78.00 & 2655 & - & - \\
\hline$\varnothing$ & $869 \pm 0$ & - & $1357 \pm 77$ & $75.0 \pm 4.2$ & $2553 \pm 145$ & - & - \\
\hline
\end{tabular}

The comparison of the residual mechanical properties to the mechanical properties of pristine straps (Table 1) shows that the ultimate tensile strength of the model straps remained almost unchanged. At the same time, their apparent fibre parallel stiffness decreased by $10.4 \%$. This might be attributed to damages observed in the fatigued laminate, i.e., delaminations and fibre-parallel matrix cracks that increase the longitudinal compliance of the laminate, but only marginally affect its ultimate tensile strength. Similar results have also been presented in [31]. The strains on the full-scale straps could not be measured, but the test revealed a significant decrease in ultimate tensile strength of the full-scale straps after a cyclic fretting fatigue loading of $25 \%$. This much stronger strength decrease is in good agreement with the reported stronger reduction in fatigue life when using a harder pin material in contact with a unidirectional CFRP ply loaded in the fibre direction [29].

\subsection{Damage Modes}

All model straps included in this study initially failed in their vertex areas (see Figure $4 \mathrm{~b}$ ) with subsequent fibre bursting in the shaft or crown area. The first visible damages of the model straps were delamination of the inner and outermost plies in the shaft with the overlapping plies. Delaminations initiated at the free ends of the overlaps and progressed towards the vertex areas where they stopped. The same fibre-parallel longitudinal cracking as described in [31] was observed on the model straps with a sacrificial twill ply during the fatigue tests prior to failure. After the premature failure in the vertex area of the straps due to the cyclic fretting fatigue loading, different types of secondary failures were observed. Figure $4 \mathrm{~d}$ shows a failed strap with the inner part of the curved section and one shaft (right) being still mostly intact, whilst the outermost plies and the opposite shaft (left) are severely damaged. Figure 4e shows a strap where both shafts and the complete curved section, including the sacrificial ply, were severely damaged. Figure $4 b$,d,e are representative images of all observed premature failures during cyclic fretting fatigue loading of the model straps. However, there appears to be no correlation between the different types of secondary failure and the (upper) load level that the straps were exposed to during testing. Figure $4 \mathrm{f}$ shows a model strap after failure due to a residual ultimate tensile strength test. All model straps tested for their pristine or residual ultimate tensile strength failed primarily in the vertex area with a more pronounced secondary fibre bursting in the shafts compared to the prematurely failed fatigue-tested straps. In case of the model straps tested for 
their residual ultimate tensile strength, this fibre bursting in the shaft resulted in more and smaller bristles due to the previous fibre-parallel damaging of the laminate.

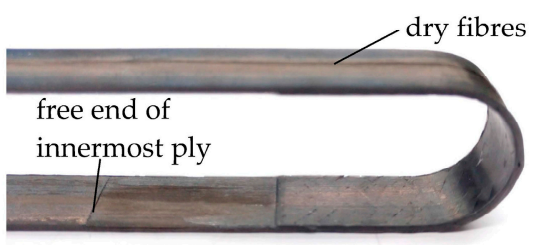

(a)

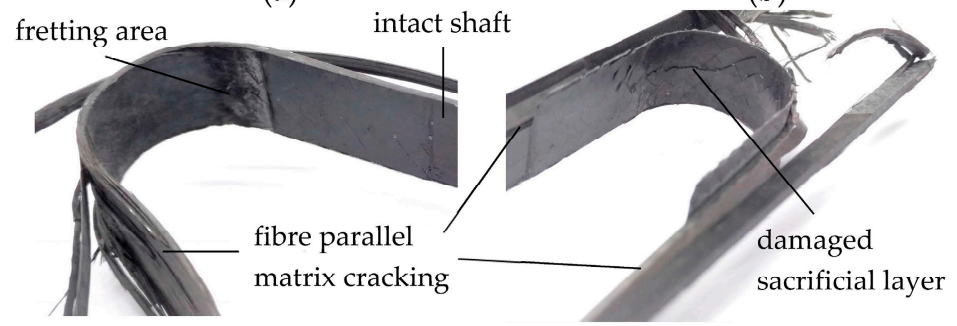

(d)

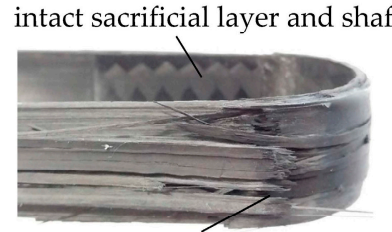

failed vertex area

(b)

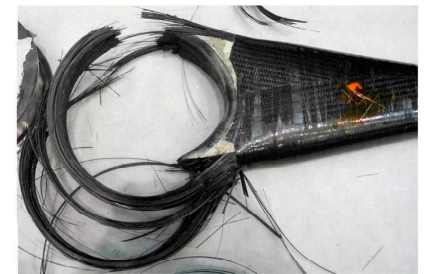

(c)

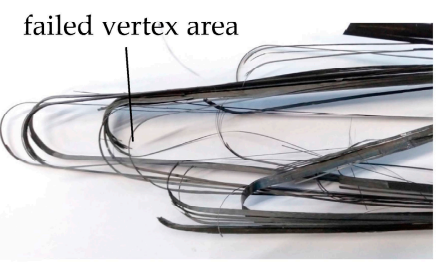

(f)

Figure 4. Damage modes in different fretting-fatigue-loaded model straps with sacrificial twill plies: (a) intact model strap prior to testing, showing the sacrificial ply and the free end of the innermost UD-ply; (b) failed model strap $\left(N_{f}=9.7 \times 10^{6}\right)$ with intact sacrificial ply; (c) failed full-scale strap FSS C with failure in the vertex area; (d) failed model strap $\left(N_{f}=2.1 \times 10^{6}\right)$ with intact sacrificial ply; (e) failed model strap with damaged and delaminated sacrificial ply $\left(N_{f}=9 \times 10^{4}\right)$; (f) failed model strap after residual tensile strength test $\left(N=3.7 \times 10^{4}\right)$.

The failure of full-scale strap FSS C occurred similar to the model straps, with initial failure in the vertex area (see Figure 4c) followed by fibre bursting in the shaft. The fatigue-tested full-scale straps showed no signs of fibre bursting in the shaft but significant fibre-parallel matrix cracking.

\subsection{Fretting Behaviour of Contacting Surfaces}

The fretting behaviour of the contacting surfaces was investigated differently for the two types of straps. By placing a transparent adhesive tape on the model strap and CFRP pin surfaces just after testing, the fretting products of these tests could be investigated. The tapes were placed on microscope slides and were examined under an optical microscope (ZEISS Stemi SV 11 in reflected-light mode). Figure 5 shows two representative pictures of the fretting products on a strap and a pin. The fretting products on the pin look similar to those described in [31], with mostly short, broken fibres and resin particles still attached to them. The fretting products on the strap are mainly small carbon particles (see [31]). However, the presence of the contacting twill ply can be clearly seen from the fibres oriented in $\pm 45^{\circ}$ (relative to the unidirectional fibres along the strap axis). However, these $\pm 45^{\circ}$ fibres were only visible on one of the two fretting areas. 


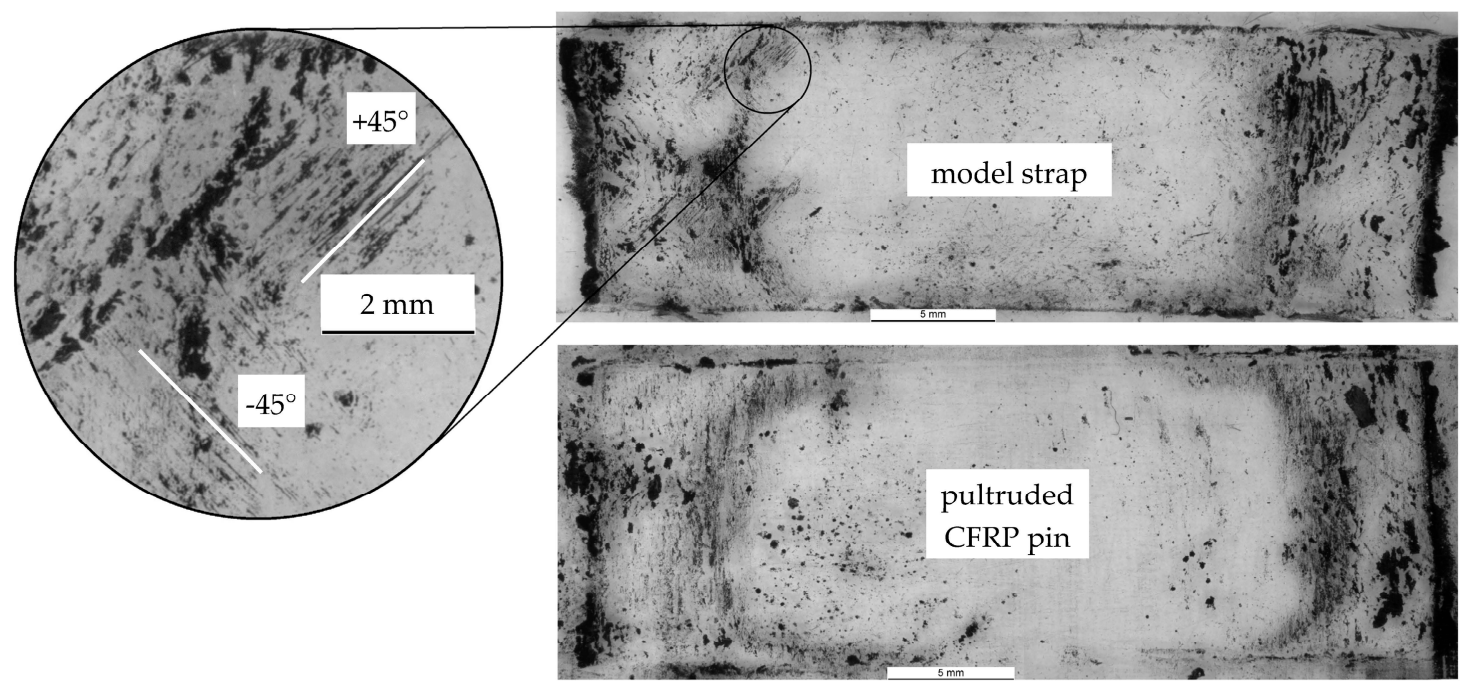

Figure 5. Fretting products of a model strap with a sacrificial twill ply (top) and a pin (bottom) after $N$ $=3.37 \times 10^{6}$. Tested at an upper load level of $20.596 \mathrm{kN}\left(\sigma_{a f s, u}=1214 \mathrm{MPa}\right)$.

The contacting surfaces of the full-scale straps were investigated under a scanning electron microscope (SEM, FEI ESEM XL30). Figure 6 shows three pictures of typical surface conditions after testing. Figure $6 \mathrm{c}$ shows the surface of FSS C in contact with the titanium connector eye in the vertex area. As the strap was not exposed to fatigue testing, the fibres (dark) are still well-embedded in the intact matrix (light) and show no signs of fibre thinning. In the regions close to the top (crown) where the relative movement between strap and connector eye is relatively small, the surface of the fatigue tested FSS A was similar. Further away from the top (crown) of the strap, see Figure $6 b$, the fibres are still intact, but the matrix suffered from the small relative movement between the strap and the connector eye. This matrix deterioration is even more pronounced in the vertex areas of fatigue tested straps, Figure 6a, where the fibres are not visibly embedded in the matrix anymore. The fibre-parallel fretting also caused fibre thinning (Figure 6a, left), and the fretting products agglomerated and covered the fibres (Figure 6a, right). These particle agglomerations consist of compressed fretting products with particle diameters of 30-100 $\mathrm{nm}$.

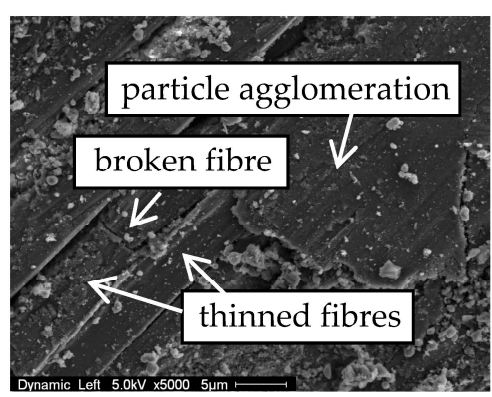

(a)

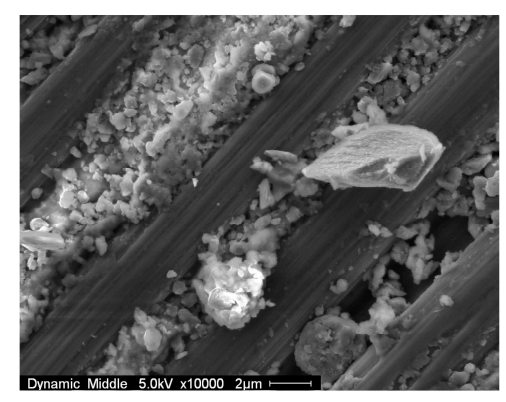

(b)

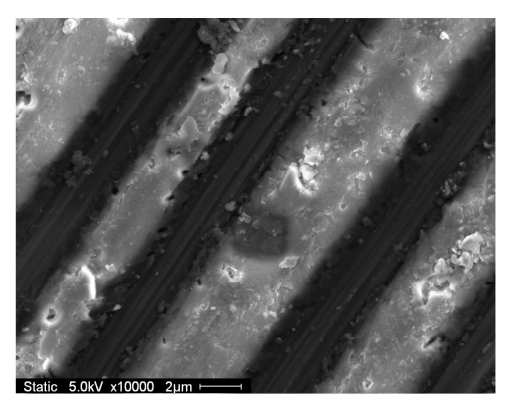

(c)

Figure 6. Typical SEM images of the full-scale strap surfaces in contact with the titanium connector eye. The images were taken after failure of the straps: (a) in the vertex area of FSS A; (b) close to the top (crown) area of FSS A; (c) in the vertex area of FSS C.

\subsection{Temperature}

Due to the high testing frequencies, the temperature on the outside of the straps was monitored during all fatigue tests. The thermocouples on the outside of the model straps measured a significant 
initial temperature increase, which reached a peak value within the first 5000 load cycles. In contrast to straps tested without a sacrificial ply [31], the temperature does not drop off significantly after this peak, but levels out at an only a slightly lower temperature (see Figure 7). The temperatures increase again once final failure of the straps is initialised. The maximum measured initial temperature peaks on the outside of the model straps were all below $50{ }^{\circ} \mathrm{C}$. With a reported glass transition temperature $(\mathrm{Tg})$ of the epoxy matrix system of $140{ }^{\circ} \mathrm{C}[35]$, these temperatures never endangered the structural integrity of the straps.

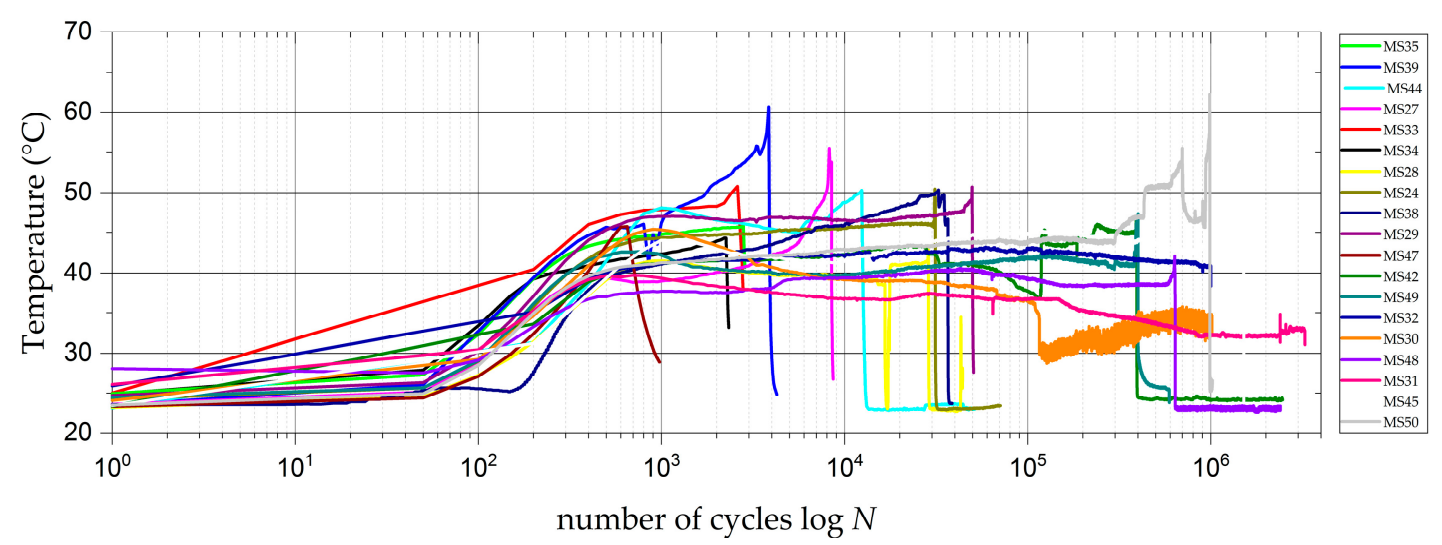

Figure 7. Temperature development on the outside of the fretting-fatigue-tested model straps with a sacrificial ply.

The temperature measurements on the outside of the full-scale strap FSS A revealed a maximum temperature of $80^{\circ} \mathrm{C}$ after $2 \times 10^{4}$ load cycles. As the temperature did not decrease within the subsequent 5000 load cycles and with a laminate thickness of $10 \mathrm{~mm}$, it had to be assumed that the temperature inside the laminate was much higher. Consequently, the test was paused and $F_{u}$ was reduced from $575 \mathrm{kN}\left(\sigma_{a f s, u}=1081 \mathrm{MPa}\right)$ to $462 \mathrm{kN}\left(\sigma_{a f s, u}=869 \mathrm{MPa}\right)$ to ensure the laminate temperature did not exceed $\mathrm{Tg}$ anywhere in the laminate. After these adjustments, the temperature did not exceed $50^{\circ} \mathrm{C}$, which was also the maximum temperature measured on FSS B during the cyclic fretting fatigue loading.

\section{Discussion}

The laminated unidirectional CFRP tension members investigated in this study were shown to be a good alternative to well-established steel tension members in terms of their fretting fatigue behaviour [44-46]. The introduction of an additional sacrificial ply protecting the load-carrying fibres during the cyclic fretting fatigue tests did not result in the expected increase in durability of the investigated model straps as the sacrificial plies did not influence the failure mode. The failure was still initiated and determined by the fibre-parallel stress concentrations in the vertex areas of the straps as described in [31]. One strap failed only after $9.7 \times 10^{6}$ load cycles, which is far above $3 \times 10^{6}$ load cycles. This has previously been reported to correspond to the fretting fatigue endurance limit of comparable straps [31]. However, complications with proper compaction of the model strap laminate during curing resulted in strongly varying thicknesses of the straps along their width. Although the laminate quality could be shown to be satisfying in general $\left(V_{f}=64 \%\right.$ and a void content of $\left.1 \%\right)$, such surface irregularities lead to stress concentrations and can act as stress inducers that have a strong influence on the fatigue behaviour of CFRP laminates [47] and should hence be eliminated in future studies.

The ultimate tensile strength tests of pristine straps revealed significantly higher failure stresses in the full-scale straps. A better laminate quality due to the robotic manufacturing of the straps with a tape-laying machine, the different pin geometry, and the lateral confinement of the full-scale strap, 
which reduced unfavorable stress concentrations in the transition zone, might, however, explain these results. The residual ultimate tensile strength tests of both the model and full-scale straps resulted in similar apparent failure stresses of both strap types at around $2500 \mathrm{MPa}$. This in turn means that the full-scale strap strength was reduced by $25 \%$ due to the fretting fatigue testing, whilst the model strap strength remained almost the same. The strong reduction of the full-scale strap strength can be tentatively attributed to the harder pin material and the larger contacting area (see [29]) acting on the laminate. The average residual failure stresses of the model straps on the other hand are almost the same $(100.3 \%)$ as the pristine tensile strength of model straps. This supports the findings in [31], where the residual strength of the straps corresponded to $99.7 \%$ of the pristine tensile strength.

The temperature measurements on the model straps showed no perturbing temperature increase due to the cyclic fretting fatigue loading. The different geometry, a thicker laminate, and different material partners in combination with a larger contacting area led to a strong temperature increase on the full-scale strap surface that was too high to disregard, and adequate measures had to be taken to inhibit the high temperatures.

The presented results are part of a pioneering study on the fretting fatigue of fibre-dominated tensile elements. The model straps used throughout this study had a similar ratio of outer to inner radius of curvature as the full-scale straps. Nevertheless, the different quasi-static strengths and the different fretting behaviour (e.g., with respect to temperature development and residual properties) of the two strap types have shown that further studies are necessary. Such studies should focus on size effects, e.g., by upscaling the model strap without lateral confinement or variation of the radius of curvature ratio, as well as on the influence of the connector eye material and geometry on the fretting fatigue behaviour. Furthermore, the fact that the $\pm 45^{\circ}$ fibres were only observed in one fretting area should be investigated as it might be a result of an uneven loading that could result in an additional reduction of the fatigue resistance of the straps. Future research should also contemplate the behaviour of pin-loaded CFRP straps exposed to harsh environmental conditions, such as salt water, humidity, and high temperatures.

Acknowledgments: The authors would like to thank the whole Mechanical Systems Engineering Laboratory at Empa Duebendorf. Special thanks go to Daniel Völki for his support during the mechanical testing and Iurii Burda for his help with the SEM. The authors owe many thanks to Empa Structural Engineering Laboratory, especially Robert Widmann, for making the full-scale strap tests possible.

Author Contributions: Fabio Baschnagel designed the mould of the model straps, helped with the manufacturing, testing and data analysis of the model straps and was strongly involved in the literature analysis and writing of the paper. Rea Härdi was responsible for the manufacturing, testing and data analysis of the model straps. Zafiris Triantafyllidis conducted and wrote the literature analysis and critically reviewed the manuscript. Urs Meier conducted all full-scale strap tests and analyzed the corresponding data. Giovanni Pietro Terrasi conceived the experiments and was very involved in the literature analysis, interpretation of the obtained results and the writing of the paper.

Conflicts of Interest: The authors declare no conflict of interest.

\section{References}

1. Schmidt, J.W.; Bennitz, A.; Täljsten, B.; Goltermann, P.; Pedersen, H. Mechanical anchorage of FRP tendons-A literature review. Constr. Build. Mater. 2012, 32, 110-121. [CrossRef]

2. Burningham, C.A.; Pantelides, C.P.; Reaveley, L.D. New unibody clamp anchors for post-tensioning carbon-fiber-reinforced polymer rods. PCI J. 2014, 59, 103-113. [CrossRef]

3. Meier, U.; Farshad, M. Connecting high-performance carbon-fiber-reinforced polymer cables of suspension and cable-stayed bridges through the use of gradient materials. J. Comput. Aided Mater. Des. 1996, 3, 379-384. [CrossRef]

4. Meier, U.; Winistoerfer, A. Multilayer, Traction Element in the Form of a Loop. Patent No. US 6,209,279 B1, 3 April 2001.

5. Pemberton, R.; Graham-Jones, J. Application of composite materials to yacht rigging. In Marine Applications of Advanced Fibre-Reinforced Composites; Woodhead Publishing: Sawston/Cambridge, UK, 2016; pp. $279-294$. ISBN 978-1-78242-250-1. 
6. Dawson, D. Yachtbuilding composites: Rigged for success. CompositesWorld 2015, 1, 60-65.

7. Cranes \& Access. Carbon fibre pendants. Cranes Access 2007, 9, 62.

8. Widmann, R.; Meier, U.; Brönnimann, R.; Irniger, P.; Winistörfer, A. Design, Construction and Monitoring of a Bowstring Arch Bridge Made Exclusively of Timber, CFRP and GFRP. In Proceedings of the 11th World Conference on Timber Engineering, Trento, Italy, 20-24 June 2010.

9. Gao, J.; Chen, C.M.; Winistörfer, A.; Meier, U. Proposal for the application of carbon fiber reinforced polymers (CFRP) for suspenders of arch bridges in China. In Proceedings of the Second Conference on Smart Monitoring, Assessment and Rehabilitation of Civil Structures, Istanbul, Turkey, 9-11 September 2013.

10. Nairn, J.A.; Hu, S. The formation and effect of outer-ply microcracks in cross-ply laminates: A variational approach. Eng. Fract. Mech. 1992, 41, 203-221. [CrossRef]

11. Bailey, J.E.; Curtis, P.T.; Parvizi, A. On the transverse cracking and longitudinal splitting behaviour of glass and carbon fibre reinforced epoxy cross ply laminates and the effect of Poisson and thermally generated strain. Proc. R. Soc. Lond. A Math. Phys. Sci. 1979, 366, 599-623. [CrossRef]

12. Flaggs, D.L.; Kural, M.H. Experimental Determination of the In Situ Transverse Lamina Strength in Graphite/Epoxy Laminates. J. Compos. Mater. 1982, 16, 103-116. [CrossRef]

13. Adolfsson, E.; Gudmundson, P. Matrix crack initiation and progression in composite laminates subjected to bending and extension. Int. J. Solids Struct. 1999, 36, 3131-3169. [CrossRef]

14. Reifsnider, K.L.; Highsmith, A.L. Characteristic damage states: A new approach to representing fatigue damage in composite materials. In Materials, Experimentation and Design in Fatigue; Sherratt, F., Sturgeon, J.B., Eds.; Westbury House: Guildford, UK, 1981; pp. 246-260.

15. Curtis, P.T. RAE Technical Report TR82031; RAE (Now DRA): Farnborough, UK, 1982.

16. Curtis, P.T. An Investigation of the Mechanical Properties of Improved Carbon Fibre Materials; RAE (Now DRA): Farnborough, UK, 1986.

17. Curtis, P.T. A Review of the Fatigue of Composite Materials; RAE (Now DRA): Farnborough, UK, 1987.

18. Morgan, P. Carbon Fibers and Their Composites; CRC Press: Boca Raton, FL, USA, 2005; p. 711. ISBN 9780824709839

19. Talreja, R. Fatigue of composite materials: Damage mechanisms and fatigue-life diagrams. Proc. R. Soc. Lond. A Math. Phys. Sci. 1981, 378, 461-475. [CrossRef]

20. Dharan, C.K.H. Fatigue Failure Mechanisms in a Unidirectionally Reinforced Composite Material. In Fatigue of Composite Materials, ASTM STP 569; Hancock, J., Ed.; American Society for Testing and Materials: West Conshohocken, PA, USA, 1975.

21. Schulte, K.; Friedrich, K.; Kutter, S. Fretting fatigue studies of carbon fibre/epoxy resin laminates. Part II: Effects of a fretting component on fatigue life. Compos. Sci. Technol. 1987, 30, 203-219. [CrossRef]

22. Jacobs, O.; Friedrich, K.; Marom, G.; Schulte, K.; Wagner, H.D. Fretting wear performance of glass-, carbon-, and aramid-fibre/epoxy and peek composites. Wear 1990, 135, 207-216. [CrossRef]

23. Jacobs, O.; Friedrich, K.; Schulte, K. Fretting fatigue of continuous carbon fibre reinforced polymer composites. Wear 1991, 145, 167-188. [CrossRef]

24. Larsen, T.Ø.; Andersen, T.L.; Thorning, B.; Horsewell, A.; Vigild, M.E. Comparison of friction and wear for an epoxy resin reinforced by a glass or a carbon/aramid hybrid weave. Wear 2007, 262, 1013-1020. [CrossRef]

25. Hu, J.; Zhang, K.; Yang, Q.; Cheng, H.; Liu, S.; Yang, Y. Fretting behaviors of interface between CFRP and coated titanium alloy in composite interference-fit joints under service condition. Mater. Des. 2017, 134, 91-102. [CrossRef]

26. Ohmae, N.; Kobayashi, K.; Tsukizoe, T. Characteristics of fretting of carbon fibre reinforced plastics. Wear 1974, 29, 345-353. [CrossRef]

27. Sung, N.-H.; Suh, N.P. Effect of fiber orientation on friction and wear of fiber reinforced polymeric composites. Wear 1979, 53, 129-141. [CrossRef]

28. Cirino, M.; Friedrich, K.; Pipes, R.B. The effect of fiber orientation on the abrasive wear behavior of polymer composite materials. Wear 1988, 121, 127-141. [CrossRef]

29. Friedrich, K.; Kutter, S.; Schulte, K. Fretting fatigue studies on carbon fibre/epoxy resin laminates: I-Design of a fretting fatigue test apparatus. Compos. Sci. Technol. 1987, 30, 19-34. [CrossRef]

30. Schulte, K.; Friedrich, K.; Kutter, S. Fretting fatigue studies on carbon fibre/epoxy resin laminates: III-Microscopy of fretting fatigue failure mechanisms. Compos. Sci. Technol. 1988, 33, 155-176. [CrossRef] 
31. Baschnagel, F.; Rohr, V.; Terrasi, G. Fretting Fatigue Behaviour of Pin-Loaded Thermoset Carbon-Fibre-Reinforced Polymer (CFRP) Straps. Polymers 2016, 8, 124. [CrossRef]

32. Schürmann, H. Konstruieren Mit Faser-Kunststoff-Verbunden; Springer: Berlin, Germany, 2007; ISBN 978-3-540-72189-5.

33. Savage, R.H. Graphite Lubrication. J. Appl. Phys. 1948, 19, 1-10. [CrossRef]

34. Toho Tenax. Product Datasheet (EU): Tenax Filament Yarn-Version 20, 2017-05-08. Available online: https:/ / www.tohotenax.com/fileadmin/PDF/Datenbl\%C3\%A4tter_en/Filament_Produktprogramm_ v24_2017-05-08_En_eu.pdf (accessed on 15 December 2017).

35. Huntsman Advanced Materials GmbH. Available online: http://www.huntsman.com/advanced_materials/ Media\%20Library/global/files/EUR_Composites\%20-\%20Composite\%20Resin_Araldite_Epoxy_RTM.pdf (accessed on 30 November 2017).

36. Carbo-link AG. Personal communication, 2015.

37. Deutsches Institut für Normung (DIN). DIN EN 2564: Aerospace Series. Carbon Fibre Laminates. Determination of the Fibre-, Resin- and Void Contents; Deutsches Institut für Normung (DIN): Berlin, Germany, 1998.

38. Hexcel Corporation. HexTow ${ }^{\circledR}$ AS4 Carbon Fiber-Product Data Sheet. Available online: http://www. hexcel.com/user_area/content_media/raw/AS4_HexTow_DataSheet.pdf (accessed on 15 December 2017).

39. Suter-Kunststoffe AG. PDF Catalog. Available online: http://www.swiss-composite.ch (accessed on 20 August 2015).

40. Winistoerfer, A. Development of Non-Laminated Advanced Composite Straps for Civil Engineering Applications. Ph.D. Thesis, University of Warwick, Warwick, UK, 1999.

41. Automated Dynamics. Available online: http://www.automateddynamics.com/automation-equipment/ tape-laying (accessed on 26 January 2018).

42. Composites One LLC. Composites One ${ }^{\circledR}$ PET Foam. Available online: http:/ /www.compositesone.com/ product/core-materials / pet-foam/ (accessed on 15 December 2017).

43. Deutsches Institut für Normung (DIN). DIN EN 2561: Aerospace Series. Carbon Fibre Reinforced Plastics. Unidirectional Laminates, Tensile Test Parallel to the Fibre Direction; Deutsches Institut für Normung (DIN): Berlin, Germany, 1995.

44. International Federation for Structural Concrete (fib). Acceptance of Stay Cable Systems Using Prestressing Steels: Recommendations; fib Bulletin 30; International Federation for Structural Concrete: Lausanne, Switzerland, 2005.

45. Chen, Q.; Liu, L. Research on Mechanical Property Test of CFRP Hanger in Steel Box Arch Bridge. Adv. Mater. Res. 2011, 255-260, 3070-3076. [CrossRef]

46. Bundesanstalt für Wasserbau. Ermittlung der Ermüdungsfestigkeit an Geschmiedeten Hängeranschlüssen; Bundesanstalt für Wasserbau: Karlsruhe, Germany, 2011; Available online: https:/ / www.baw.de/content/ files/forschung_entwicklung/documents / A39510110194.pdf (accessed on 8 February 2018).

47. Talreja, R.; Singh, V.R. Damage and Failure of Composite Materials; Cambridge University Press: Cambridge, UK, 2012; ISBN 9780521819428.

(C) 2018 by the authors. Licensee MDPI, Basel, Switzerland. This article is an open access article distributed under the terms and conditions of the Creative Commons Attribution (CC BY) license (http://creativecommons.org/licenses/by/4.0/). 